\title{
Teachings from the French database of TTR familial amyloidotic polyneuropathy (TTR-FAP): large genetic and phenotypic heterogeneity, usefulness of TTR gene testing.
}

David Adams ${ }^{1 *}$, Cecile Cauquil ${ }^{1}$, Clovis Adam $^{2}$, Celie Labeyrie ${ }^{1}$, Guillemette Beaudonnet ${ }^{4}$, Anne Mantel $^{3}$, Marie Theaudin ${ }^{1}$, network Cornamyl ${ }^{5}$

From First European Congress on Hereditary ATTR amyloidosis

Paris, France. 2-3 November 2015

\section{Introduction}

TTR-FAP is progressive, disabling, irreversible and lifethreatening neuropathy due to a point mutation of TTR gene with autosomal dominant transmission. France is a non endemic European country. To study the impact of labeling French reference center for FAP (NNERF) and building of a national network CORNAMYL.

\section{Methods}

In 1986-2014 period, 482 FAP patients were registered in NNERF's database. All carried amyloidogenic TTR gene mutations and Congo positive amyloid deposit (CPAD). To report genotypic and phenotypic varieties of FAP in France in 2008-2014 period and the sensitivity of the tools for diagnosis.

\section{Results}

In 2008-2014 period: 180 new TTR-FAP cases were identified, in 14 additionnal geographical departments (total 81/100), with 9 further TTR gene mutations (total 41).

Mean age was 60 (22-89), a late onset ( $>$ or $=50 \mathrm{y}$ ) in $69 \%$. Sex ratio: 2.16 . Positive family history of FAP $55 \%$. Portuguese origin $18.3 \%$. Diagnosis of FAP was delayed by $2.93 y$ (0.2-13.5) after first symptoms; $69 \%$ had walking difficulties including $39 \%$ requiring aid.

Five phenotypes were identified: Small Fiber Polyneuropathy (PNP) (43\%), All-Fiber SensoryMotor-PNP (25\%), Upper Limbs neuropathy (NP) (17\%), Ataxic NP (14\%), Motor NP (2\%). CPAD after nerve biopsy in $19 / 26 \mathrm{pts}$
(73\%), Labial Salivary Gland Biopsy (LSGB) in 91/128 pts (71\%); 76\% required multiple biopsies.

\section{Conclusions}

The French network for TTR-FAP allows to identify new TTR-FAP cases in most of geographical departments with varied phenotypes. The larger use of TTR gene analysis in idiopathic aggressive polyneuropathy cases will help to accelerate diagnosis of TTR-FAP.

\section{Authors' details}

${ }^{1}$ Chu Bicetre, Neurology (NNERF), 94270, Le Kremlin Bicêtre, France. ${ }^{2}$ Chu Bicetre, Pathology, 94270, Le Kremlin Bicêtre, France. ${ }^{3}$ Chu Bicetre, Molecular Biology, 94270, Le Kremlin Bicetre, France. ${ }^{4}$ Chu Bicetre, Neurophysiology, 94270, Le Kremlin Bicêtre, France. ${ }^{5}$ French Network For Fap, 94270, Le Kremlin Bicetre, France.

Published: 2 November 2015

\section{doi:10.1186/1750-1172-10-S1-P27}

Cite this article as: Adams et al: Teachings from the French database of TTR familial amyloidotic polyneuropathy (TTR-FAP): large genetic and phenotypic heterogeneity, usefulness of TTR gene testing.. Orphanet Journal of Rare Diseases 2015 10(Suppl 1):P27.

${ }^{1}$ Chu Bicetre, Neurology (NNERF), 94270, Le Kremlin Bicêtre, France Full list of author information is available at the end of the article 